\title{
Internet of Things: Ideological Prospects and Its Social Implication to the Muslim Community
}

\author{
Mohammed Yunusa Jeddah', Auwal Adam Sa'ad², Adamu Abubakar \\ 'Dept. of Electrical and Computer Engineering, International Islamic University Malaysia \\ 2IIUM Institute of Islamic Banking and Finance, International Islamic University Malaysia \\ 3Dept. of Computer Science, International Islamic University Malaysia \\ yunusa.j@live.iium.edu.my, auwal@iium.edu.my, adamu@iium.edu.my
}

\begin{abstract}
This paper sought after identifying some likely traps a Muslim might fall into because of the geometric improvement in the field of network connectivity, with a strict focus on Internet of Things (IoT). The principal aim was to reawaken the people (Muslims) on their sole purpose on this earth as they swim in the pool of development and ease of doing things brought about by this technology. A Muslim should remain focused, despite the lures of things around him. This technology is studied together with the obvious problems it has come with. Findings showed some scary deep black holes a Muslim may fall into without really knowing he is into rebellious acts against the dictates of his religion, Islam. Due to their vulnerability, the Internet of Things devices could be compromised and used in committing illegal acts against humanity. This study would declare that these devices are so vulnerable that they can be used in perpetrating things like identity theft, snooping (privacy violation) and different other forms of crimes which are obviously not in conformity with Islamic dictates. Furthermore, it would additionally assert that the Internet of Things is one of the technologies which carry along so much to worry about in terms of ethics, social relationship and by extension even religious concerns (as stated in this paper). It was also instituted that the producers of these devices are yet to discover (or make a proper attempt to) a convincing solution to this problem. These findings establish the accomplishment of the fact that Muslims should always study deeply and be skeptical and investigative towards utilizing each technology to the fullest without infringing on the rights of Allah.
\end{abstract}

Keywords - identification internet of things, social impact, Muslim community

\section{INTRODUCCTION}

Advancement in the direction of the Internet of Things is perhaps going to spring up several social and ethical issues and arguments in the world, some of which have surfaced in connection with the existing Internet and ICT at large. Such issues could be in the form of trust loss, privacy violations, data misuse, copyright issues, digital divide, identity theft, control difficulties and speech freedom and expression and having information access [1]. Nevertheless, in loT, most of these problems take a new dimension considering an increase in complications. However, a Muslim has a way of identifying what is considered good or bad, ethical or nonethical because he has rigid obedience to his source of guidance. Imam Ali (AS) said, "Islam is submission, and submission is a certainty, and certainty is a belief, and belief is an expression, and expression is undertaking, an undertaking is an action" At this point, Imam Ali (AS) offers six stages (submission, certainty, belief, expression, undertaking, and action) for Islam [2].

In this paper, an attempt was made to bring to the notice of the Muslim community, the possible social
Changes/effects that this novel technology, the Internet of Things may pose.

\section{A. Concept of IoT}

The core idea of the Internet of Things (IOT) is to arm real physical devices with computing and communication ability in order for them to be able to interact with one another for the common good [3]. Internet of things simply means a lot of devices getting an IP address, or at least devices that are addressable on the Internet [4]. That is describing the universal communication which is not only about monitoring and communication, but also about controlling these devices [5]. IoT technologies let devices or things which are not computers, to behave smartly and make collective decisions which are helpful to certain applications. They provide the ability for things (devices) to see, hear, think, or act by letting them exchange information and coordinate with others to reach resolutions that can be as serious as saving buildings or lives [6-7].

\section{B. Social/Society}

The social sciences refer to a social group as two or more individuals who relate to each other, have identical characteristics and mutually have a wisdom of unity [8] The 
social group which comes in diverse sizes and varieties is defined by Researchers within the social identity tradition as "a group is defined in terms of that identify themselves as a member of the group.

\section{Muslims}

The term 'Muslim', that was mentioned in the Holy Qur'an at 90 places [9] denotes one who 'submits' or 'commits' to Allah. The name Muslims was given by the Almighty Allah to the followers of the religion of Islam, which was the region followed by Abraham peace be upon him, Allah the almighty said; "It is the religion of your father Abraham, He "Allah" named you Muslims before "in former scriptures" and in this revelation." (Qur'an 22, 78) Allah (SWT) says: "fear Allah as He should be feared and do not die except as Muslims [in submission to Him]" (Qur'an 3:102). This clearly shows that a Muslim is someone who must have a total submission to the will of Allah (SWT).

The people who practice the religion of Islam are those who are referred to as Muslims. Islam must be considered, as a standard which cannot be split and whose teachings cannot be scrutinized in solitude. Muslims must abide by the Qur'an, which is the primary source of guidance [10], as demonstrated by the way of life of the Holy Prophet, Muhammad (peace be upon him).

\section{Community}

According to community is an amalgamation of two basics [11]:

1) A network of effect loaded affairs amongst a group of people, relationships that repeatedly traverse and strengthen one another rather than just one-on-one or chainlike specific affairs;

2) An amount of obligation to a set of communal norms, values, and meanings, and a collective history and identity, to a certain culture.

\section{Muslim Community/World}

The Muslim community is a universal community of multiplicity, heterogeneity, and color. Muslims are taught to receive every single Muslim (and non-Muslim) with total disdain to their race, color, or origin [12]. The Muslim community is referred to as the best by Allah (SWT) in the Glorious Qur'an: "You are indeed the best community that has ever been brought forth for [the good of] mankind..." (Qur'an 3:110 as translated by Asad).

The Holy Qur'an is the medium for learning the will of Allah and for weighing the success of a life lived in accord with it. This is what makes it shape the personal and communal lives of Muslims in various ways [13].

\section{RELATED WORK}

Going through some literature, it could be concluded that the Internet of Things is an expansion of the Internet, which is very tough to separate between the two technologies. According to Sholla et al. [14], interpretational issues apart, there are high predictions for the IoT's potential to greatly revolutionize our lives, not always undoubtedly for the better. However, this report focuses on the impact of IoT on the society in general, not on a community, like the Muslim community. Even though it was clear that "an end-to-end fully-informed network associated with IOT is for environment and devices only [15], but values also matter. Hosseini et al. [16] argue that Information Technology has not only brought Islamic literature to the doorstep of Muslims globally but also become a vital tool for the propagation of the religion around the globe and it help clear up the misconceptions of non-Muslims about Islam. However, the possibility of committing an act of sin through IT was not considered in their article. Hence the need to alert the Muslim Umma to likely dangers one can fall into.

Detenber and Cheong [17] proposed a project that use of the internet for religious purposes. They compare the various religious adherent's uses of the internet for religious activities. However, this project fails to identify the likely acts of corruptions that could be perpetrated by the users of the internet and its position the religion.

\section{A. Social/Societal Concerns on the Internet of Things}

According to Christ et al. [18] reveal that In the contemporary world, Muslims are attracted and influenced by several pressures that will upset them to a larger or smaller extent. This is a pointer to the fact that Muslims must be very vigilant in every aspect of their social as well as societal interaction with both humans (Muslims and nonMuslims) and any technology developed. This technology could be the trap to make him deviate from the straight path he is directed to follow the Quran. Allah mentioned in the Holy Qur'an: "This is my straight path, so follow it, and follow not diverse paths, lest they scatter you from its road." (Qur'an 6:154)

The loT has the potential to bring about higher business yield, improved energy, transport efficiency, better control and assessing capacity in production and supply processes. Nevertheless, there are needs to balance this in contrast to real menaces to security, privacy, and resilience recognized and unforeseen [19]. Hence, the need for Muslims to look at these facets critically to avoid falling into the trap, like the one emphasized by [5], because he can be committing an act of sin without really knowing.

\section{B. Implications of IoT on Muslim Community}

Islam as a complete and perfect religion (Qur'an 5:3), tend to put every innovation to scrutiny before accepting it. As for technology, it's expected to help Muslims appreciate the existence and capability of their creator, to obey Him using the same technology. Here we attempt to elaborate some 
of the pit holes which the Muslim may fall into while enjoying the development brought about by the Internet of Things.

The proposed ideological framework of IOT social implication to the Muslim community is presented in Figure 1. The framework lies within the three spectrums namely: "Things", "Connecting" and "the three components of IoT architecture (Application, Network, Perception)". The things in the Internet of Things (IOT) could either be a "Biochip transponder" attached within the body of anything, or "Monitor implant" mostly embedded in the human beings, or "Built-in sensors" to be attached on any surface. These are collectively refered to as "things". The connection of these things are accessed through the Internet. The Internet protocol that deals with the connection of these things are in three architectural layer, namely: "Application", "Network" and "Perception" [20]. "Perception layer" is the lower layer, popularly refer to as a southbound. It's also refer to as the physical layer of IOT that defines the acceptable rules for the devices that would participate in the working of IoT. This will enable a general standard for which sensing and gathering information about the environment will be same in everywhere. The network layer is the middle layer that is responsible for connecting to "things" and the Internet. That is, it defines the rules that are generally acceptable for allowing the "things"/devices with IOT capability to be on Internet. This layer provides the features that are used for transmitting information over the connected devices on the on IoT environment, finally the upper layer, is called "the application layer" which is responsible for setting out all the program supporting the delivery of data over the network of the IoT. It set out various rules that are general acceptable for the programs that can be deployed on the IoT.

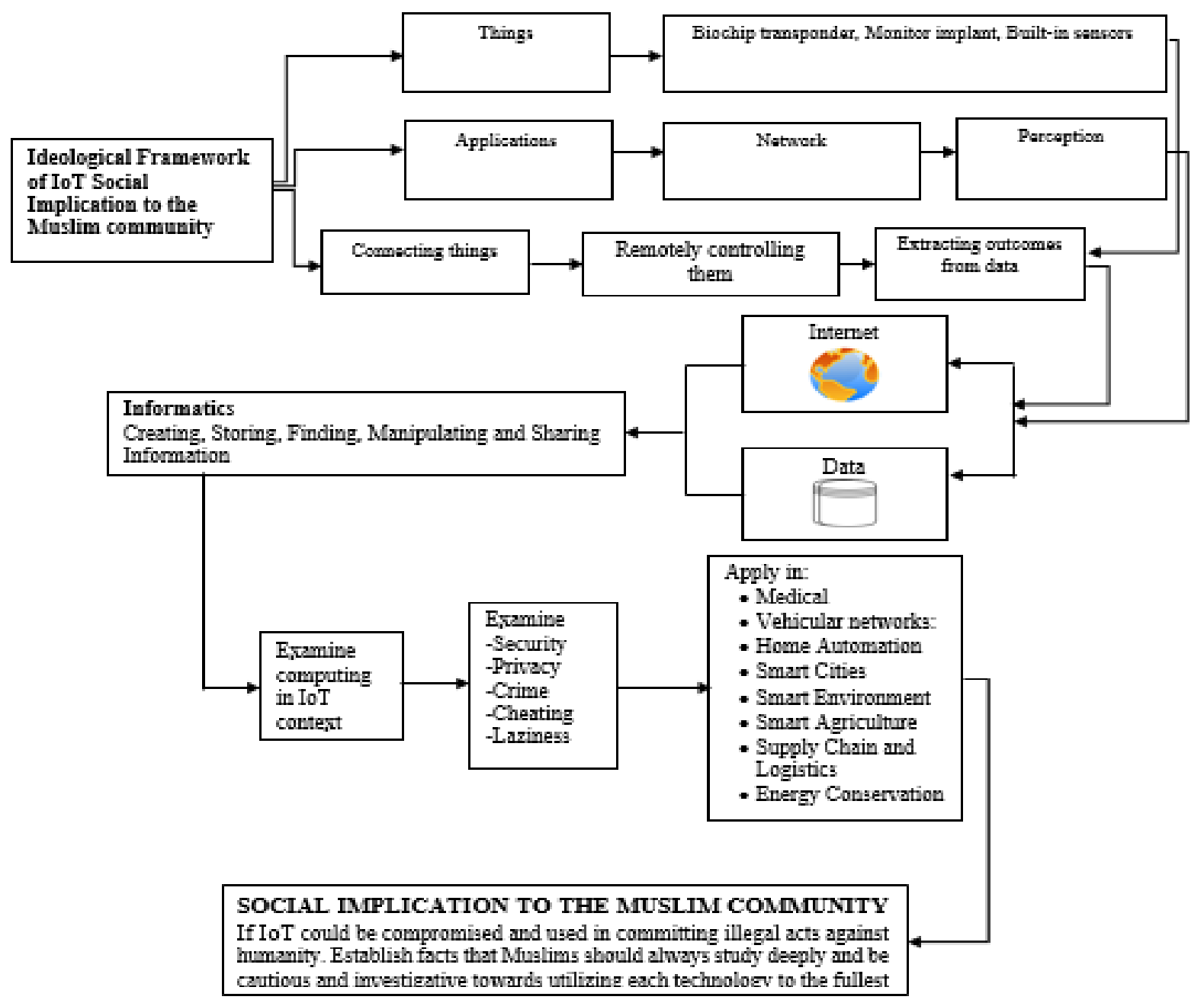

Fig.1 Ideological Framework of Social Implication of IoT to the Muslim Community

The connections of things based on the layered protocol enable makes it to be remotely control. Subsequently, data will be extracted for further evaluation. At this point, it can be concluded that IOT key component are "Internet and Data". Hence, they can utilize for creating, storing, finding, manipulating and Sharing information. IoT can be both tool 
and process, that is why it is necessary to examine computing in loT context in order to determine "Security", "Privacy", "Crime", "Cheating", "Laziness". Hence, the application of IoT could be from various are like "Medical", "Vehicular networks", "Home Automation", "Smart Cities", "Smart Environment", "Smart Agriculture", "Supply Chain and Logistics" and "Energy Conservation". Therefore, the social implication to the Muslim community open application of Iol is necessary. Some of the crucial aspect are if IoT could be compromised and used in committing illegal acts against humanity or it can establish facts that Muslims should always study deeply and be cautious and about it.

Among the crucial issues related to the proposed ideological framework of IOT social implication to the Muslim community are: Security, Privacy, Crime, Cheating, Laziness

\section{Security}

Security should be regarded as very significant when it comes to the issue of peace. All the factors that bring about peace contribute to the formation of security. Nevertheless, possibly the foremost thing that comes to people's mind when they think of security has to do with laws. Laws are vital for security as they are the basis of unobjectionable behavior. Absolutely, Islam is a belief that not only make available general attitudes for life but also offers comprehensive laws. Peace and security will certainly be the utmost goal of any society.

The Internet of Things, as interesting and attractive as it looks, is full of security breaches.

\section{Privacy}

"Believers let those your right hand owns and those who have not come of age ask permission of you three times before the dawn prayer, when you put aside your garments, in the heat of noon, and after the night prayer. These are the three occasions of privacy. There is no fault in you or them, apart from these that they go about you, you are of each other. As such Allah makes plain to you his verses; Allah is the knower, the wise. And when children reach the age of puberty, let them ask permission as those before they asked permission. As such Allah makes clear to you his verses. Allah is the knower, the wise.” (Qur'an, 24:58-59). “... And do not spy or backbite each other..." (Qur'an 49:12). These verses stress on the value placed on privacy in Islam. Internet of Things is coming together with its privacy violations.

WikiLeaks's trove of CIA papers discovered that webconnected televisions can be used to covertly record discussions. What could be more intrusion into privacy than this? A Muslim must be reminded that any attempt to use such methods in order to gain access to someone's conversations could be tantamount to tampering the victim's privacy.

\section{E. Crime}

It has been established in digital crimes when devices like mobile, IP camera, or any other smart object communicate with one another, a substantial amount of information is exchanged and retained [21]. This exchanged information is likely to retrieved and used by a criminal, due to the vulnerability of these devices and commit any sort of crime, otherwise known as cybercrime. The point to note here is not that the owner of the internet connected device uses it to commit a crime only, but, his device might be compromised by Botnet [22] and used to commit a crime. As Muslims, we need to study the position of that kind of crime in Islam to avoid committing an act of crime indirectly.

Islam provides to people's desire for peace and tranquillity and consequently takes necessary lawful measure to protect the society against unruly elements. It's a necessity to protect the society from the actions of hoodlums and criminals. Social life ought to be devoid of trouble and secure [23]. Cybercrime could fall under punishable offenses, according to Islamic perspective. The penalty for theft is clearly stated in the glorious Quran: "As to the thief, male or female, cut off his or her hands" (Qur'an $5: 38)$.

Many Islamic scholars have expressed concern on cybertheft and regarded it as punishable theft as revealed in the Qur'an, however there are few concern on the issue of hirz (protective items) which is one of the requirements stipulated in the theft law, that the item stolen should be in a highly secured place and not in an open space, however must of the cybertheft are done after a successful inversion that leads to uproot all the security apparatus placed to protect the items stolen, therefore it is regarded as a punishable act to be punished by Hudud laws, in another words Cybertheft could fall under the category spoken about in the above verse of the Glorious Qur'an.

\section{F. Cheating}

Cheating, which can take any form is amongst the major tribulations that can face a society. Even though cheating appears somewhat very irrelevant, but its effect cannot be described, because it can lead to the destruction of lives and properties. Islam frowns at cheating in its entirety. Allah (SWT) dislikes cheating and even the people who indulge in it. In the Glorious Quran, He has cautioned those who indulge in cheating of calamitous penalties. Allah says: "Woe to Al-Mutaffifoon (those who give less in measure and weight). Those who, when they have to receive by measure from men, demand full measure, and when they have to give by measure or weight to (other) men, give less than due" (Qur'an 83:1).

Pay per click (PPC) is currently one of the best if not the form online advertisement. PPC is an online advertisement (Ad) model where advertisers place their adverts on web pages, the moment the user of the website clicks on the ad, 
the host (website owner) is paid by the advertiser. This point needs to be looked at critically because Botnets could be used to commit cheat. This kind of cheating could take the shape of controlling this Bots to be performing the act of clicks on a website. This is clearly a form of cheating, in which Muslims are asked to desist from.

Our intention here is to alert the Muslim community; the potential dangers they may fall into without really knowing.

\section{G. Laziness}

Imam Al-Ragheb refers to laziness as "lack of energy and enthusiasm of doing something that you should not lack energy/enthusiasm for". Ordinarily, we should not be devoid of vigor/eagerness to accomplish our prayers, go to work, or to study and improve ourselves, but if we do then that's laziness. The term "Kasal" is the Arabic name for laziness, was mentioned twice in the Holy Qur'an, about the hypocrites and their state of prayer:

"Verily, the hypocrites seek to deceive Allah, but it is He Who deceives them. And when they stand up for As-Salat (the prayer), they stand with laziness and to be seen of men, and they do not remember Allah but little". (Qur'an 4:142).

"And nothing prevents their contributions from being accepted from them except that they disbelieved in Allah and in His Messenger (Muhammad صلى الله عليه وسلم), and that they came not to As-Salat (the prayer) except in a lazy state, and that they offer not contributions but unwillingly." (Qur'an 9:54).

According to Aleisa and Renaud [24] IoT makes the whole life more expedient and effortless. This sound very attractive because our devices are on the verge of taking responsibility for our duties. We as Muslims should not be over joyous of this development, because it may come a time when some sections of our major lbadah would be left for these ostensible smart objects. A time may come when our smartwatch would inform the amplifier that it's time for azan and then the amplifier which might have been equipped with azan software just call for solat. How do we envision a time when we would be so reliant on these socalled smart devices to an extent that we dedicate the future (for training/learning) of our children to them? To teach them the Qur'an and the entire deen.

The point we are trying to raise here is that we as Muslims shouldn't be as lazy as the extent of the aforementioned. We should be reminded that acts of Ibadah could only be done by human himself.

\section{v. CONCLUSION}

In conclusion, as we enthusiastically welcome the advancement in technology, as Muslims, we should at the same time enjoined ourselves to remain focused. We should make sure we harvest the fruits brought by any technology development while at the same time, remind ourselves, that no technology, whatever the joy, happiness, and ease of doing things that did not come along with side effects.

We therefore, emphatically enjoin the muslim community to caution and maitain their focus, dispite the sweetness of advancement in technology.

\section{REFERENCES}

[1] R. Weber, Pereira, Â. G., Dechesne, F., Timmermans, J., Van, R. K., \& Lehn, H. Vom. (2013). Fact sheet - Ethics Subgroup IoT - Version 4. o. Delft University of Technology Chair Ethics Subgroup IoT Expert Group, 1-21.

[2] IUS(2012, September 12). Islam: The total submission to the will of Allah. Retrieved May 19, 2018, from https://www.ius.org.uk/islamthe-total-submission-to-the-will-of-allah

[3] K.M. Alam, M. Saini, M., \& El Saddik, A.. Toward social internet of vehicles: Concept, architecture, and applications. IEEE Access, 3, 343-357. (2015)

[4] J.R.C. Nurse, Creese, S., \& D. De Roure, Security Risk Assessment in Internet of Things Systems. IT Professional, 19(5), 20-26, 2017.

[5] H. Ning, \& Z. Wang, loT-A Internet of Things Architecture. Communications, 3, 461-463, 2011.

[6] H. Geng, (Ed.). (2017). Internet of things and data analytics handbook. John Wiley \& Sons.

[7] A.I. Abubakar, H. Chiroma, S.A. Muaz, \& L.B. Ila, (2015). A Review of the Advances in Cyber Security Benchmark Datasets for Evaluating Data-Driven Based Intrusion Detection Systems. In SCSE (pp. 221-227).

[8] M. Hewstone, \& H. Giles, (1997). Social groups and social stereotypes, 270-283. Retrieved from http://link.springer.com/chapter/10.1007/978-1-349-25582-5_22

[9] R. Aggarwal (2019), The Meaning of The Word 'Muslim' Retrieved from https://www.aquila-style.com/the-meaning-of-the-wordmuslim-2/

[10] S.L. Douglass, \& M.A. Shaikh, Defining Islamic Education Differentiation and Applications. Current Issues in Comparative Education, 7(1), 5-18, 2004

[11] A. Etzioni, The Good Society. Seattle Journal for Social Justice, 1(1), 83-96. (1992)

[12] M.J. Ibrahim (2017) Racism in The Muslim Community: Are We Really One? Retrieved from https://mvslim.com/racism-in-the-muslimcommunity-are-we-really-one/

[13] Ed John L. Esposito 2018 "Qur'an." In the Islamic World: Past and Present. Retrieved from: http://www.oxfordislamicstudies.com/article/opr/t243/e275).

[14] S. Sholla, R.N. Mir, \& M.A. Chishti, Eventuality of an apartheid state of things: An Ethical Perspective on the Internet of Things. International Journal of Technoethics (IJT), 9(2), 62-76, 2018.

[15] A. Abubakar, M.T. El-Gammal, \& A.A. Alarood. End-To-End FullyInformed Network Nodes Associated with $433 \mathrm{MHz}$ Outdoor Propagation Environment. International Journal of Computing and Digital Systems, 10, 1-19, 2020.

[16] S.E. Hosseini, A.A. Ramchahi, \& R.J. Yusuf, The impact of Information Technology on Islamic Behaviour. Journal of Multidisciplinary Engineering Science and Technology (JMEST), 1(5), 135-141, 2014.

[17] B.H. Detenber, \& P.H. Cheong, The Internet and Religion in Singapore: A National Survey, (65). (2006)

[18] J. Christ, J. Christ, \& T. Muslim, T. Who is a Muslim and Why Communicate the Gospel of Jesus Christ to him ? 1-6. (1995)

[19] I. Brown, J. Crump, D. Boos, W. Dutton, K. Kinder, C. Kortuem, R. Marshall, The Societal Impact of the Internet of Things. Bcs, 14 Retrieved from http://www.bcs.org/upload/pdf/societal-impactreport-feb13.pdf. (2013).

[20] O. Mashal, T.Y. Alsaryrah, C.Z. Chung, W.H. Yang, W.-H. Kuo, and D. P. Agrawal, "Choices for interaction with things on Internet and underlying issues," Ad Hoc Networks, vol. 28, pp. 68-90, 2015. 
[21] P.H. Rughani (2017). IoT Evidence Acquisition - Issues and Challenges, 10(5), 1285-1293. Retrieved from http://www.ripublication.com

[22] R. Chinn, R. (2015). Botnet Detection: Honeypots and the Internet of Things. Unpublished doctoral dissertation). University of Arizona.
[23] E.E. Okon, E. E. (2014). Hudud punishments in Islamic criminal law. European Scientific Journal, 10(14), 227-238.

[24] N. Aleisa, \& K. Renaud, K. Privacy of the Internet of Things: A Systematic Literature Review (Extended Discussion), 1-10. https://doi.org/10.24251/HICSS.2017.717 Analytics Handbook Internet of Things and Data Analytics. (n.d.). (2016) 